\title{
Asymmetric properties of rod cGMP Phosphodiesterase 6 (PDE6): structural and functional analysis
}

\author{
Bilal M Qureshi ${ }^{1 * \dagger}$, Elmar Behrmann ${ }^{1,5+}$, Johannes Schöneberg ${ }^{2,6}$, Justus Loerke ${ }^{1}$, Jörg Bürger ${ }^{1}$, Thorsten Mielke ${ }^{1,3}$, \\ Jan Giesebrecht ${ }^{1,7}$, Frank Noé$^{2}$, Klaus Peter Hofmann ${ }^{1,4}$, Christian M T Spahn ${ }^{1}$, Martin Heck ${ }^{1}$
}

From 7th International Conference on cGMP Generators, Effectors and Therapeutic Implications

Trier, Germany. 19-21 June 2015

Photoreceptor cGMP Phsophodiesterase 6 (PDE6) is the effector molecule of visual signal transduction and mediates fast response of light signals. The rod holo-PDE6 comprises catalytic $(\alpha, \beta$; each $\sim 90 \mathrm{kDa})$ and two identical inhibitiory $(\gamma ; \sim 10 \mathrm{kDa})$ subunits. The catalytic subunits comprise N-terminal tandem GAF domains followed by C-terminal catalytic domains and isoprenylations for membrane-association. Contrary to activation of other tandem GAF comprising PDEs, PDE6 activation does not occur via cGMP-induced concerted conformational changes. Rather two copies of the $\alpha$-subunit of retinal G-Protein $\left(\mathrm{G \alpha}^{*}\right)$, transducin, activate PDE6 by partially displacing the inhibitory subunits. The activation of PDE6 has therefore been described as a "de-inhibition". The affinity of Ga* to PDE6 and the enzymatic activity of the intermediary 1:1 complex is highly disputed, therefore a conclusive activation model is lacking so far.

Our combined structural, enzymatic and computational investigations deal with the activation-mechanism of PDE6. Our cryo electron microscopy (EM) structure of PDE $\alpha \beta$ catalytic core shows an elongated bell-shaped structure with symmetric side-by-side arrangement of the two subunits with flexible membrane-binding domains. A comparison with nearly full-length inactive PDE2A structure [1] suggests that less compaction of both subunits and higher degree of conformational freedom of the catalytic domains result in constitutive activation of PDE6 $\alpha \beta$, which is kept inactive by the

\footnotetext{
* Correspondence: bilal.qureshi@charite.de

+ Contributed equally

'Biophysics and Medical Physics, Charité - Universitätsmedizin Berlin, 10117 Berlin, Germany

Full list of author information is available at the end of the article
}

inhibitory $\gamma$ subunits. Furthermore, the structure of PDE6 suggests $\mathrm{G}^{*}$ * binding-sites pointing to opposing faces. The enzymatic characterization using $\mathrm{G \alpha}^{*}$ titration of the PDE6 however reveal striking asymmetry of the two catalytic subunits with a high and a low affinity binding site for $\mathrm{Ga}^{*}$. Occupancy of the PDE6 with one $\mathrm{G}^{*}$ induces negligible activity, whereas occupancy with two copies of $\mathrm{G \alpha}^{*}$ leads to full enzyme activity. Such an activation mechanism constitutes a "coincidence switch" that allows noise filtering (i.e., spontaneously produced $\mathrm{G}^{*}$ * do not activate PDE6). Our spatiotemporal simulation work indeed confirms that spontaneously generated $\mathrm{Ga}^{*}$ lead to the formation of singly occupied PDE6 and only a high local concentration of $\mathrm{G \alpha}^{*}$, as produced by an active receptor (rhodopsin), leads to doubly $\mathrm{G \alpha}^{*}$ occupied effector complex. Therefore the localized large concentration of $\mathrm{G \alpha}^{*}$ combined with the asymmetric properties of PDE6 constitutes a "density switch" that allows suppression effector level noise and reliable reporting of single quantum events in rod photoreceptor cells.

\begin{abstract}
Authors' details
'Biophysics and Medical Physics, Charité - Universitätsmedizin Berlin, 10117 Berlin, Germany. ${ }^{2}$ Department of Mathematics, Computer Science and Bioinformatics, Freie Universität Berlin, 14195 Berlin, Germany. ${ }^{3}$ Microscopy \& Cryo Electron Microscopy Group, Max-Planck Institut für Molekulare Genetik, 14195 Berlin, Germany. ${ }^{4}$ Zentrum für Biophysik und Bioinformatik, HumboldtUniversität zu Berlin, 10115 Berlin, Germany. ${ }^{5}$ Present address: Research Group Structural Dynamics of Proteins, Center of Advanced European Studies and Research (caesar), 53175 Bonn, Germany. ${ }^{6}$ Present address: Department of Molecular \& Cell Biology, University of California at Berkeley, Berkeley, CA 94720, USA. ${ }^{7}$ Present address: FEI VSG (Visualization Science Group), Zuse Institut Berlin, 14195 Berlin, Germany.
\end{abstract}

Published: 2 September 2015 


\section{Reference}

1. Pandit J, Forman MD, Fennell KF, Dillman KS, Menniti FS: Mechanism for the allosteric regulation of phosphodiesterase $2 \mathrm{~A}$ deduced from the X-ray structure of a near full-length construct. PNAS 2009, 106:18225-18230.

doi:10.1186/2050-6511-16-S1-A76

Cite this article as: Qureshi et al: Asymmetric properties of rod cGMP

Phosphodiesterase 6 (PDE6): structural and functional analysis. BMC

Pharmacology and Toxicology 2015 16(Suppl 1):A76.

Submit your next manuscript to BioMed Central and take full advantage of:

- Convenient online submission

- Thorough peer review

- No space constraints or color figure charges

- Immediate publication on acceptance

- Inclusion in PubMed, CAS, Scopus and Google Scholar

- Research which is freely available for redistribution

Submit your manuscript at www.biomedcentral.com/submit 